\title{
The Relationship Between Core Stability and Leg Stiffness in Male and Female Athletes
}

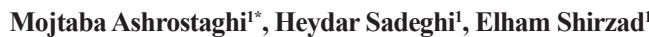

1. Department of Physical Education and Sport Sciences, Faculty of Physical Education and Sport Sciences, Kharazmi University, Tehran, Iran.

Crtation: Ashrostaghi M, Sadeghi H, Shirzad E. The Relationship Between Core Stability and Leg Stiffness in Male and Female Athletes. Physical Treatments. 2016; 5(4):211-218.

Article info:

Received: 25 Jun. 2015

Accepted: 29 Oct. 2015

\section{Keywords:}

Leg stiffness, Core stability, Sex, Injury risk, Athletic performance

\begin{abstract}
A B S T R A C T
Purpose: Core stability and leg stiffness are two determinant mechanisms in athletic performance and risk injury. This study aimed to investigate the gender differences and relationship of these two factors in athletes.

Methods: In this cross-sectional study, core stability and leg stiffness of 12 male and 12 female Iranian squash players at national level were examined utilizing McGill's test (including flexor, extensor, left side bridge and right side bridge tests) and hopping test at $2.2 \mathrm{~Hz}$. Total core stability was calculated by integrating its 4 parts and their ratios which were considered as balance criteria of core stability. Leg stiffness was normalized to body mass. Independent $t$ test and Pearson correlation test were performed to investigate the research purposes. All statistical analyses were done using SPSS 16.0.

Results: The core stability in two groups had no significant difference. However, the female group had more unbalanced core stability than male group. Leg stiffness was higher in male group than the female group but this difference disappeared after normalizing body mass. The significant correlation between core stability and leg stiffness was explored $(\mathrm{r}=0.46, \mathrm{P}=0.02)$.

Conclusion: Although the female participants of the study achieved the same scores as males, their unbalanced core and possible adopted strategy to compensate their less stiff structures, may expose them to greater injury risk. These results are noteworthy for designing training programs and choosing proper movement strategies. The significant, but weak correlation between variables indicates the power transmitting role of core musculature in leg stiffness regulation during hopping that should be considered.
\end{abstract}

\section{Introduction}

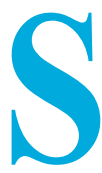

tability and stiffness are two key components for optimal performance [1]. These terms are originally mechanical concepts that have been subjected to human movement research during previous decades [2, 3]. In mechanics, the material resistance to deformation under loading is called stiffness [4] and the ability of a loaded structure to maintain equilibrium is called stability [5]. In living tissues, muscular contrac-

\footnotetext{
* Corresponding Author:

Mojtaba Ashrostaghi, PhD

Address: Department of Physical Education and Sport Sciences, Faculty of Physical Education and Sport Sciences, Kharazmi University, Tehran, Iran Phone: +98 (910) 6769305

E-mail: mojtabaashr@yahoo.com
} 
tions and neural controls are added to mechanical properties of structures in passive mode [6]. Therefore, these mechanical concepts in human body transform into neuro-biomechanic ones and their definitions partly change.

The concept of stability in human body may imply to whole body stability or the stability of each one of its segments [7]. The body core is one of the segments that its stability has been discussed since three decades ago [3]. The concept of stiffness in human body is also applied at different levels [2]. At the lowest level, the stiffness of structures such as tendons, muscles or even a muscle fiber $[8,9]$, at moderate level, the stiffness of joint and its surrounding structures $[4,10]$, and at the highest level, leg stiffness [2] have been discussed.

The core may not be a main power generator, however it serves as a power transmitter in human movements [7]. Insufficient core stability and unbalanced core may result in increasing the risk injury and low back pain $[11,12]$. Leg stiffness is also considered as an injury risk factor [2], especially in the case of gender differences in anterior cruciate ligament injury [13], and as an important parameter in some athletic movements [14]. The determinant role of stability and stiffness, in both normal life activities and competition performances, has motivated the researchers to evaluate these variables in different populations: athlete and non-athletes, females and males, healthy and injured. Given the gender differences in athletic performances [15] and risk injury [13, 14] and in order to explore some causes of these differences, the current study examined and compared these variables between healthy male and female athletes. These two mechanisms do not operate independently, rather a close relationship between stability and stiffness in core, trunk, and torso areas has been reported $[1,7]$.

Theoretically, the core stability and trunk posture, may also be a determinant factor in leg stiffness during hopping. The role of ankle, knee, and hip joints on leg stiffness has been already examined [16] but role of core area has been overlooked. Therefore, the three aims of this study were to compare the core stability and imbalance between female and male athletes, to compare the leg stiffness between female and male athletes, and finally to investigate the relationship between core stability and leg stiffness in athletes.

\section{Materials and Methods}

Twenty-four Iranian squash players (at national level) composed of 12 males [mean(SD) weight: $80.1(7.4) \mathrm{kg}$, mean(SD) height: $181(6) \mathrm{cm}$, mean(SD) age: $24.6(4.1)$ y] and 12 females [mean(SD) weight: 61.6(5.4) kg, mean(SD) height: $164(5) \mathrm{cm}$, mean(SD) age: 23.1(6.2) y)] were volunteered to participate in this cross-sectional study. The statistical population comprised all male and female Iranian squash players. The study subjects was were selected by convenience sampling method. Then, they completed medical questionnaire and signed their informed consents. The exclusion criteria were having lower extremity injuries, operation history, arthritis, and neurological disorders. All procedures were explained to the subjects thoroughly. The study was approved by the Ethics Committee of local University.

Following a common 5-minute warm up program on treadmill, all participants performed 2 separate tests to assess their core stability and leg stiffness. The procedure of these tests is explained below.

\section{Core stability test}

Several tests are being claimed to measure different aspects of core stability, including strength, endurance, flexibility, motor control, and function [12]. Much of core stability is achieved by less than $25 \%$ of the maximum contraction level [1]. Therefore core muscle endurance tests, such as McGill's test, may be the best measure to quantify core stability [12]. McGill's test is one of the most reliable core stability tests that measures isometric muscle endurance of the body core in 4 domains; the flexor test, the extensor test, and left and right side bridge tests [17]. This test was used in the current study. The position of subjects in each test was as follows:

The flexor test: the subject was in a sit up position with back resting against a jig angled at 60 degrees from the floor. The jig was pulled back by $10 \mathrm{~cm}$ to begin the test.

The extensor test: the upper body cantilevered out over the end of the test bench with pelvis, knees, and hips secured.

Side bridge test: the subjects should lie in side bridge position while leaning their elbow and feet and lifting their hips off the ground. In this position, a straight bridge is created from head to toe. This test was done for right and left side individually.

Subjects held these positions as long as possible. A handheld stopwatch was used to measure how long each participant could hold each isometric position. Furthermore sum of the recorded times was considered as total core stability. The variables measured by flexor, extensor, left side bridge, and right side bridge tests were respectively abbreviated as Fle, Ext, R, and L, also total 
core stability was abbreviated as Tot. Based on the previous studies, there are some indices considered as balance criteria of core area [11]. If the ratio of Fle to Ext is more than 1 or the ratio of $\mathrm{R}$ or $\mathrm{L}$ to Ext is more than 0.75 or the deviation of $\mathrm{R}$ to $\mathrm{L}$ is more than 0.05 , the core may be unbalanced. Thus, these ratios (Fle/Ext, R/Ext, L/Ext, and $\mathrm{R} / \mathrm{L}$ ) were also calculated as balance criteria of core area.

\section{Leg stiffness test}

Leg stiffness is based on mass-spring model that describes some human movements such as running and hopping. Bilateral hopping test with frequency of $2.2 \mathrm{~Hz}$, one of the most reliable tests to assess the leg stiffness [18], was used in this study. The participants were instructed to hop vertically and land on a take-off point with fully extended joints. They had to complete 15 successive hops. A digital metronome helped the subjects to maintain the considered frequency. This frequency is close to the preferred frequency of human hopping and the subjects get easily adjusted to it. However, all participants were allowed to practice as much as they needed. The leg in the stance phase of this task, behaves as a linear spring. Leg stiffness $(\mathrm{K})$ is defined as the ratio of maximum ground reaction force $\left(\mathrm{F}_{\text {max }}\right)$ to maximum vertical displacement of center of mass $(\Delta y)$ [19]. Dalleau et al. [20] developed an indirect method to estimate the $\mathrm{K}$ value from temporal parameters (Equation 1). $\mathrm{K}$ in this method is dependent on contact time $\left(\mathrm{t}_{\mathrm{c}}\right)$, flight time $\left(\mathrm{t}_{\mathrm{f}}\right)$, and body mass $(\mathrm{m})$.

$$
K=F_{\max } / \Delta y=\left[m \pi\left(t_{f}+t_{c}\right)\right] /\left\{t_{c}^{2}\left[\left(t_{f}+t_{c}\right) / \pi-t_{c} / 4\right\}\right.
$$

The indirect method was used in this research. A highspeed camera recorded the task in sagittal plane at 300 fps. Video films were then used to measure both contact and flight times. The temporal parameters of 5 consecutive hops from the $6^{\text {th }}$ to $10^{\text {th }}$ hop (of 15 hops) were averaged and together with body mass were inserted in Equation 1. Some researchers have suggested that leg stiffness is related to body mass. Therefore in the current study, leg stiffness was also normalized relative to body $\operatorname{mass}\left(\mathrm{K}_{\mathrm{n}}=\mathrm{K} / \mathrm{m}\right)$.

The Kolmogorov-Smirnov test was used to assess the normality of data. Independent $t$ test was performed to compare the variables between males and females. To assess the relationships between the core stability and leg stiffness, the Pearson productmoment correlation was computed. The level of statistical significance was set at $\mathrm{P}<0.05$. All statistical analyses were done using SPSS 16.0.

\section{Results}

\section{Core stability and balance}

The results of McGill's test and balance criteria (Table 1) showed that none of the holding times was significantly different between two groups. However, Fle/Ext ratio was significantly higher in females than males. The averages of Fle/Ext, R/L, and L/Ext were beyond the critical ratios for female group. In the male group, only the average value of $\mathrm{R} / \mathrm{L}$ was a little out of normal range.

Table 1. Core stability and balance criteria in female and male groups and for all participants.

\begin{tabular}{|c|c|c|c|c|}
\hline Tests & $\begin{array}{c}\text { Females } \\
(n=12) \\
\text { Mean } \pm S D\end{array}$ & $\begin{array}{c}\text { Males } \\
(n=12) \\
\text { Mean } \pm S D\end{array}$ & P-values & $\begin{array}{l}\text { All participants } \\
(\mathrm{N}=\mathbf{2 4}) \\
\text { Mean } \pm \mathrm{SD}\end{array}$ \\
\hline Flexor (Fle), s & $104.3 \pm 61.9$ & $100.5 \pm 68.8$ & 0.888 & $102.4 \pm 64.0$ \\
\hline Extensor (Ext), $s$ & $85.8 \pm 38.9$ & $120.9 \pm 48.7$ & 0.064 & $103.3 \pm 46.7$ \\
\hline Right side bridge ( $R$ ), $s$ & $55.5 \pm 34.4$ & $72.3 \pm 32.0$ & 0.228 & $63.9 \pm 33.6$ \\
\hline Left side bridge (L), $s$ & $68.6 \pm 38.9$ & $80.0 \pm 37.0$ & 0.472 & $74.3 \pm 37.6$ \\
\hline Total core stability (Tot), s & $314.3 \pm 156.2$ & $373.7 \pm 166.1$ & 0.376 & $344.0 \pm 160.6$ \\
\hline Fle/Ext & $1.31 \pm 0.63 * *$ & $0.81 \pm 0.44$ & $0.032^{*}$ & $1.06 \pm 0.59 * *$ \\
\hline$R / L$ & $0.79 \pm 0.27^{* *}$ & $0.93 \pm 0.25 * *$ & 0.202 & $0.86 \pm 0.26^{* *}$ \\
\hline R/Ext & $0.65 \pm 0.31$ & $0.62 \pm 0.23$ & 0.777 & $0.64 \pm 0.27$ \\
\hline L/Ext & $0.80 \pm 0.23 * *$ & $0.67 \pm 0.16$ & 0.126 & $0.73 \pm 0.20$ \\
\hline
\end{tabular}

${ }^{*} \mathrm{P}<0.05$, significant difference between females and males.

**Denotes the average value beyond the critical ratio. 
Table 2. Leg stiffness parameters in female and male groups and in all participants.

\begin{tabular}{|c|c|c|c|c|}
\hline Tests & $\begin{array}{l}\text { Females } \\
(n=12) \\
\text { Mean } \pm S D\end{array}$ & $\begin{array}{c}\text { Males } \\
(n=12) \\
\text { Mean } \pm S D\end{array}$ & P-values & $\begin{array}{c}\text { All participants } \\
(\mathrm{N}=24) \\
\text { Mean } \pm S D\end{array}$ \\
\hline Hopping frequency $(f), \mathrm{Hz}$ & $2.19 \pm 0.04$ & $2.20 \pm 0.02$ & 0.138 & $2.20 \pm 0.04$ \\
\hline Mass (m), kg & $61.6 \pm 5.4$ & $80.1 \pm 7.4$ & $0.000^{*}$ & $70.8 \pm 11.4$ \\
\hline Contact time $\left(t_{c}\right), s$ & $0.29 \pm 0.04$ & $0.27 \pm 0.04$ & 0.360 & $0.28 \pm 0.04$ \\
\hline Flight time $\left(\mathrm{t}_{\mathrm{f}}\right), \mathrm{ms}$ & $0.17 \pm 0.04$ & $0.19 \pm 0.04$ & 0.239 & $0.18 \pm 0.04$ \\
\hline Leg stiffness $(\mathrm{K}), \mathrm{kN} \cdot \mathrm{m}^{-1}$ & $14.96 \pm 2.55$ & $21.26 \pm 4.58$ & $0.001^{*}$ & $18.11 \pm 4.84$ \\
\hline Normalized leg stiffness $\left(\mathrm{K}_{\mathrm{n}}\right), \mathrm{kN} \cdot \mathrm{kg}-1 \cdot \mathrm{m}^{-1}$ & $0.24 \pm 0.04$ & $0.26 \pm 0.05$ & 0.242 & $0.25 \pm 0.04$ \\
\hline
\end{tabular}

${ }^{*} \mathrm{P}<0.05$, significant difference between females and males.

PHYSICAL TREA TMENTS

Table 3. Correlation coefficients of core stability and leg stiffness.

\begin{tabular}{ccc}
\hline Tests & Leg stiffness (K) & Normalized leg stiffness (Kn $)$ \\
\hline Flexor (Fle) & 0.31 & 0.38 \\
\hline Extensor (Ext) & $0.46^{*}$ & $0.41^{*}$ \\
\hline Right side bridge (R) & $0.43^{*}$ & $0.48^{*}$ \\
\hline Left side bridge (L) & 0.32 & 0.37 \\
\hline Total core stability (Tot) & $0.42^{*}$ & $0.46^{*}$ \\
\hline
\end{tabular}

${ }^{*} \mathrm{P}<0.05$, significant correlation coefficient.

\section{Leg stiffness}

The hopping test results (Table 2) showed that hopping frequency was close to the metronome beat. Thus the task was successfully performed by participants. Males were significantly heavier than females. $\mathrm{K}$ value was higher in male group than female group but $\mathrm{K}_{\mathrm{n}}$ was not significantly different between two groups.

\section{Relationship between core stability and leg stiffness}

All of the correlation coefficients between core stability and leg stiffness were positive in a range of 0.31 to 0.48 (Table 3). Total core stability, flexor test, and extensor test had statistically significant correlations with $\mathrm{K}$ and $\mathrm{K}_{\mathrm{n}}$.

\section{Discussion}

The current study quantified core stability using McGill's test and leg stiffness using hopping test (at $2.2 \mathrm{~Hz}$ ) in female and male squash players. No gender differences were observed with regard to core stability (neither in total core stability nor in each one of four parts) and mass normalized leg stiffness. However, the positive correlation between these two variables was observed.

\section{Core stability and balance}

The average records of subjects in McGill's test were 102.4, 103.3, 63.9, and 74.3 seconds (respectively for the flexor, extensor, right and left side bridge tests) resulted in average total core stability of $344 \mathrm{~s}$. Previous researchers have recorded the values from less than 300 $\mathrm{s}$ [12] to more than $600 \mathrm{~s}$ [21] in various groups. McGill et al. [17] in a research on non-athletes reported that women demonstrated longer times than men for extensor test, but not for other parts. In contrast, Evans et al. [22] found that male athletes had equivalent holding times on extensor and flexor tests compared to female athletes, but longer times for side bridge tests than females. The current study found no statistically significant differences between male and female squash players with regard to core stability indices. This might be due to their training programs.

Given the critical ratios presented by McGill [11], female core musculature was more unbalanced than male 
ones. Females in 3 of 4 criteria (Fle/Ext, R/L and L/Ext) had the average values out of balanced zone but males was outbalanced in one index $(\mathrm{R} / \mathrm{L})$. Therefore, females seem to be at higher risk of low back pain. Note that the critical ratios have been obtained in non-athlete subjects. Whether these ratios are valid for the special groups such as squash players, needs further research.

\section{Leg stiffness}

Leg stiffness was higher in the male group compared to the female group but after normalizing to body mass, this difference disappeared. These findings are in agreement with previous studies on non-athletes $[13,14]$. The stiffness of knee, ankle, and structures of these joints are the major determinants of leg stiffness in hopping [16]. Research conducted on knee extensors and ankle plantar flexors (active open kinetic chain tests) revealed that the stiffness of these structures in females was about $55 \%$ to $65 \%$ of males stiffness $[23,24]$. Normally similar result should be observed in leg stiffness that is claimed to be the combination of its different structure stiffness [2]. Padua et al. [13] explained that female subjects employ a different hopping strategy than males to compensate their more compliant structures. Females try to increase their knee extensor and plantar flexor stiffness through increasing the activity level of these muscles. This strategy leads to anterior translation of tibia and increases the quadriceps to hamstring activity ratio that are two major causes of anterior cruciate ligament injury [13].

\section{Relationship between core stability and leg stiffness}

The correlation of total core stability and Kn was 0.46 indicating that core stability may account for up to $20 \%$ of the variance of leg stiffness. Although the normalization did not have much influence on this relationship, increased somewhat the correlation coefficient from 0.42 to 0.46 . Hobara et al. [16] in a regression analysis revealed that ankle, knee, and hip stiffness altogether explained more than $80 \%$ of the variance of leg stiffness in maximal hopping at $1.2 \mathrm{~Hz}$. Thus, our finding may imply on the last regulating of leg stiffness during hopping. Hopping with a more straight leg decreases the joint moments (because of joint alignment with ground force vector) and increases the leg stiffness [25]. Apparently, the ability of core musculature to hold the spine and trunk in a straight posture can also modulate the leg stiffness through reducing lumbopelvic joint moment. Unlike the lower extremity stiffness for which several measurement methods in different levels have been presented [8, 10], core stiffness (also named trunk or torso stiffness) has been investigated in a few studies [26, 27]. Consider- ing the close relationship of stability and stiffness in this area, the positive correlation of core stability and $\mathrm{K}$ value probably indicates the role of core stiffness in the amount of stiffness while hopping. Accordingly, the name "overall musculoskeletal stiffness" used by Rabita et al. [28] may be more appropriate than leg stiffness.

Already, Nesser et al. [29] reported significant but not strong relationship between core stability and power performances in athletes. Our finding confirmed their report supported the McGill's opinion [7] who emphasized the secondary role of core muscles as a power transmitter. In fact, a more effective core is one that can provide more stability and stiffness. Such a core increases the potential energy storage during the eccentric phase of motion [25] and decreases the energy leaks during transmission of power generated at hips toward upper body [7] and so helps optimal performance without having an important contribution on power generation.

Although the core has been usually considered as a unit that its muscles work synergistically [29], it could actually be evaluated separately, too. Synergists work together locally to produce motion in an isolated joint but muscle chains work together to move and stabilize multiple joints [30]. These chains, called anatomy trains [31] or muscle slings [32], facilitate the rotatory movements and transfer the forces through the trunk, especially from the lower to the upper body [30]. Anatomy trains include front, back, and lateral lines [31]. In each part of McGill's test, corresponding line is mainly activated. Correlation coefficients of two parts, the extensor and right side bridge tests, with leg stiffness were statistically significant. Dupeyron et al. [25] reported that an abdominal strengthening program affected leg stiffness during hopping.

However, our findings emphasized the role of back line and right lateral line. The weakness of these parts in female group was evident, so improving them could result in eliminating the imbalance and increasing the leg stiffness without need of dangerous overactivity of muscles. It is noteworthy that in side bridge tests, lateral lines are generally activated but in flexor and extensor tests, front and back lines are not usually activated, because the hip and lower limb are fixed. Replacing the extensor and flexor tests with the more general tests, like the plank test, or replacing side bridge tests with the more specific tests, may increase the homogeneity of McGill's test.

Female participants $\mathrm{Kn}$ in this study was equal to male ones. Similar finding on non-athletes has attributed to 
dangerous overactivity of female muscles. Unlike the previous studies on non-athletes, no gender differences were observed with regard to core stability criteria. However, the female group demonstrated more unbalanced core status than males. Balanced development of core abilities is necessary to avoid the risk of low back pain. The positive significant correlation between core stability and leg stiffness seems to indicate the power transmitting role of core in leg stiffness regulation. Additionally, the suggestions were presented for homogenization of McGill's test.

\section{Acknowledgment}

This paper was extracted from Mojtaba Ashrostaghi' $\mathrm{PhD}$ thesis, Faculty of Physical Education and Sport Sciences, Kharazmi University, Iran.

\section{Conflict of Interests}

The authors declared no conflicts of interest.

\section{References}

[1] McGill S. Ultimate back fitness and performance. $4^{\text {th }}$ ed. Waterlo: Backfitpro Incorporated; 2009.

[2] Butler RJ, Crowell HP, Davis IMC. Lower extremity stiffness: implications for performance and injury. Clinical Biomechanics. 2003; 18(6):511-7. doi: 10.1016/s0268-0033(03)00071-8

[3] Hibbs AE, Thompson KG, French D, Wrigley A, Spears I Optimizing performance by improving core stability and core strength. Sports Medicine. 2008; 38(12):995-1008. doi: $10.2165 / 00007256-200838120-00004$

[4] Latash ML, Zatsiorsky VM. Joint stiffness: Myth or reality? Human Movement Science. 1993; 12(6):653-92. doi 10.1016/0167-9457(93)90010-m

[5] Bergmark A. Stability of the lumbar spine: a study in mechanical engineering. Acta Orthopaedica. 1989; 60(230):1-54. PMID: 2658468

[6] Panjabi MM. The stabilizing system of the spine. Part I: Function, dysfunction, adaptation, and enhancement. Journal of Spinal Disorders \& Techniques. 1992; 5(4):383-89. PMID: 1490034

[7] McGill S. Core training: Evidence translating to better performance and injury prevention. Strength \& Conditioning Journal. 2010; 32(3):33-46. doi: 10.1519/ssc.0b013e3181df4521

[8] Fukashiro S, Hay C, Nagano A. Biomechanical behavior of muscle-tendon complex during dynamic human movements. Journal of Applied Biomechanics. 2006; 22(2):131-47. doi: $10.1123 /$ jab.22.2.131
[9] Proske U, Morgan D. Tendon stiffness: methods of measurement and significance for the control of movement. A review. Journal of Biomechanics. 1987; 20(1):75-82. doi: 10.1016/0021-9290(87)90269-7

[10] Ditroilo M, Watsford M, Murphy A, De Vito G. Assessing musculo-articular stiffness using free oscillations: theory, measurement and analysis. Sports Medicine. 2011; 41(12):1019-032. doi: 10.2165/11591470-000000000-00000

[11] McGill S. Low back disorders: evidence-based prevention and rehabilitation. $2^{\text {nd }}$ ed. Champaign, IL: Human Kinetics; 2007.

[12] Waldhelm A, Li L. Endurance tests are the most reliable core stability related measurements. Journal of Sport and Health Science. 2012; 1(2):121-28.

[13] Padua DA, Carcia CR, Arnold BL, Granata KP. Gender differences in leg stiffness and stiffness recruitment strategy during two-legged hopping. Journal of Motor Behavior. 2005; 37(2):111-26. doi: 10.3200/jmbr.37.2.111-126

[14] Hobara H, Kato E, Kobayashi Y, Ogata T. Sex differences in relationship between passive ankle stiffness and leg stiffness during hopping. Journal of Biomechanics. 2012; 45(16):2750754. doi: 10.1016/j.jbiomech.2012.09.008

[15] Thibault V, Guillaume M, Berthelot G, El Helou N, Schaal $\mathrm{K}$, Quinquis $\mathrm{L}$, et al. Women and men in sport performance: the gender gap has not evolved since 1983. Journal of Sports Science \& Medicine. 2010; 9(2):214-23. doi: 10.1371/journal. pone. 0019007

[16] Hobara H, Muraoka T, Omuro K, Gomi K, Sakamoto M, Inoue $\mathrm{K}$, et al. Knee stiffness is a major determinant of leg stiffness during maximal hopping. Journal of Biomechanics. 2009; 42(11):1768-771. doi: 10.1016/j.jbiomech.2009.04.047

[17] McGill SM, Childs A, Liebenson C. Endurance times for low back stabilization exercises: clinical targets for testing and training from a normal database. Archives of Physical Medicine and Rehabilitation. 1999; 80(8):941-94. doi: 10.1016/s0003-9993(99)90087-4

[18] Joseph CW, Bradshaw EJ, Kemp J, Clark RA. The interday reliability of ankle, knee, leg, and vertical musculoskeletal stiffness during hopping and overground running. Journal of Applied Biomechanics. 2013; 29(4):386-94. doi: 10.1123/ jab.29.4.386

[19] McMahon TA, Cheng GC. The mechanics of running: How does stiffness couple with speed? Journal of Biomechanics. 1990; 23:65-78. doi: 10.1016/0021-9290(90)90042-2

[20] Dalleau G, Belli A, Viale F, Lacour J, Bourdin M. A simple method for field measurements of leg stiffness in hopping. International Journal of Sports Medicine. 2004; 25(3):170-76 doi: 10.1055/s-2003-45252

[21] Nesser TW, Lee WL. The relationship between core strength and performance in division I female soccer players. Journal of Exercise Physiology Online. 2009; 12(2):21-28.

[22] Evans K, Refshauge KM, Adams R. Trunk muscle endurance tests: reliability, and gender differences in athletes. Journal of Science and Medicine in Sport. 2007; 10(6):447-55. doi: 10.1016/j.jsams.2006.09.003

[23] Granata KP, Wilson SE, Padua DA. Gender differences in active musculoskeletal stiffness. Part I: Quantification in 
controlled measurements of knee joint dynamics. Journal of Electromyography and Kinesiology. 2002; 12(2):119-26. doi: 10.1016/s1050-6411(02)00003-2

[24] Kubo K, Kanehisa H, Fukunaga T. Gender differences in the viscoelastic properties of tendon structures. European Journal of Applied Physiology. 2003; 88(6):520-26. doi: 10.1007/s00421-002-0744-8

[25] Dupeyron A, Hertzog M, Micallef JP, Perrey S. Does an abdominal strengthening program influence leg stiffness during hopping tasks? Journal of Strength \& Conditioning Research. 2013; 27(8):2129-133. doi: 10.1519/ jsc.0b013e318278f0c7

[26] Vette AH, Masani K, Wu N, Popovic MR. Multidirectional quantification of trunk stiffness and damping during unloaded natural sitting. Medical Engineering \& Physics. 2014; 36(1):102-09. doi: 10.1016/j.medengphy.2013.10.005

[27] Lee BC, McGill SM. Effect of Long-term Isometric Training on Core/Torso Stiffness. Journal of Strength \& Conditioning Research. 2015; 29(6):1515-526. doi: 10.1519/ jsc.0000000000000740

[28] Rabita G, Couturier A, Lambertz D. Influence of training background on the relationships between plantarflexor intrinsic stiffness and overall musculoskeletal stiffness during hopping. European Journal of Applied Physiology. 2008; 103(2):163-71. doi: 10.1007/s00421-008-0679-9

[29] Nesser TW, Huxel KC, TincherJL, Okada T. The relationship between core stability and performance in Division I football players. Journal of Strength \& Conditioning Research. 2008; 22(6):1750-754. doi: 10.1519/jsc.0b013e3181874564

[30] Page P, Frank C, Lardner R. Assessment and treatment of muscle imbalance: the Janda approach. Champaign, IL: Human Kinetics; 2010.

[31] Myers TW. Anatomy trains: myofascial meridians for manual and movement therapists. Edinburgh: Churchill Livingstone; 2009.

[32] Pool-Goudzwaard A, Vleeming A, Stoeckart R, Snijders C, Mens J. Insufficient lumbopelvic stability: a clinical, anatomical and biomechanical approach to 'a-specific'low back pain. Manual Therapy. 1998; 3(1):12-20. doi: 10.1054/ math.1998.0311 
